\title{
DILEMAS DO UNIVERSO FEMININO
}

\author{
A PARTICIPAÇÃO FEMININA NO AMBIENTE CORPORATIVO \\ AUMENTOU CONSIDERAVELMENTE, CONFERINDO \\ RESPONSABILIDADES CADA VEZ MAIORES A ESSE PÚBLICO. \\ NA ATUALIDADE, O PRINCIPAL DESAFIO DAS MULHERES É MANTER \\ 0 EQUILÍBRIO ENTRE A VIDA PROFISSIONAL, FAMILIAR E PESSOAL
}

| POR TANIA CASADO

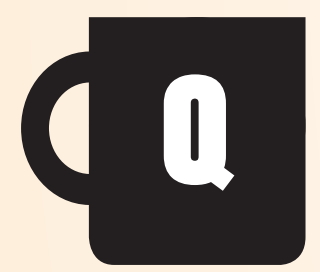

uase 50 anos depois da publicação do livro A Mística Feminina (1963), de Betty Friedan, que trouxe à tona aspectos do universo das mulheres, os quais repercutiram em todo o mundo e introduziram profundas mudanças no modo de ver a atuação delas fora da esfera doméstica, ainda nos deparamos com muitas questões sobre a sua participação no ambiente externo ao lar. Cada vez mais divididas entre as obrigações com a família e as necessidades da carreira, elas têm experimentado angústia, culpa e solidão, da mesma forma que Friedan reportou sobre si mesma: "Eu senti isso primeiro como um ponto de interrogação em minha própria vida, como esposa e mãe de três crianças pequenas, meio culpada e, portanto, meio dividida [...] usando minhas habilidades e formação no trabalho que me tirava de casa".

O incremento da participação feminina no ambiente corporativo contempla tanto o aumento constante dessa população nas organizações, como, ainda que timidamente, os graus de responsabilidade e atuação em níveis hierárquicos mais altos. Isso tem resultado em demandas maiores do papel profissional das mulheres, sem que sejam atenuadas suas tarefas na esfera familiar.
A prática e a pesquisa em modelos de gestão têm demonstrado que profissionais, organizações e a sociedade em geral parecem não estar preparados para tais avanços. É necessário que todas as instâncias envolvidas e atingidas pela crescente participação feminina nas corporações unam-se para refletir, encontrar novas alternativas e empenhar esforços para a criação de estratégias e programas que atendam à complexidade dos problemas derivados desse fato. No Brasil, as discussões necessárias devem incluir desde a legislação trabalhista até políticas e procedimentos organizacionais, passando, obrigatoriamente, pelas concepções geralmente aceitas sobre gênero, trabalho e vida pessoal.

\section{PARTICIPAÇÃO DA MULHER NO MERCADO}

Dados recentes do Instituto Brasileiro de Geografia e Estatística (IBGE) mostram que entre 2003 e 2011 houve um crescimento comparativamente maior da participação das mulheres do que dos homens no mercado de trabalho em todos os grupamentos de atividades estudados (indústria, comércio, serviços prestados a empresas, administração pública, serviços domésticos, etc), com exceção da área de construção. 


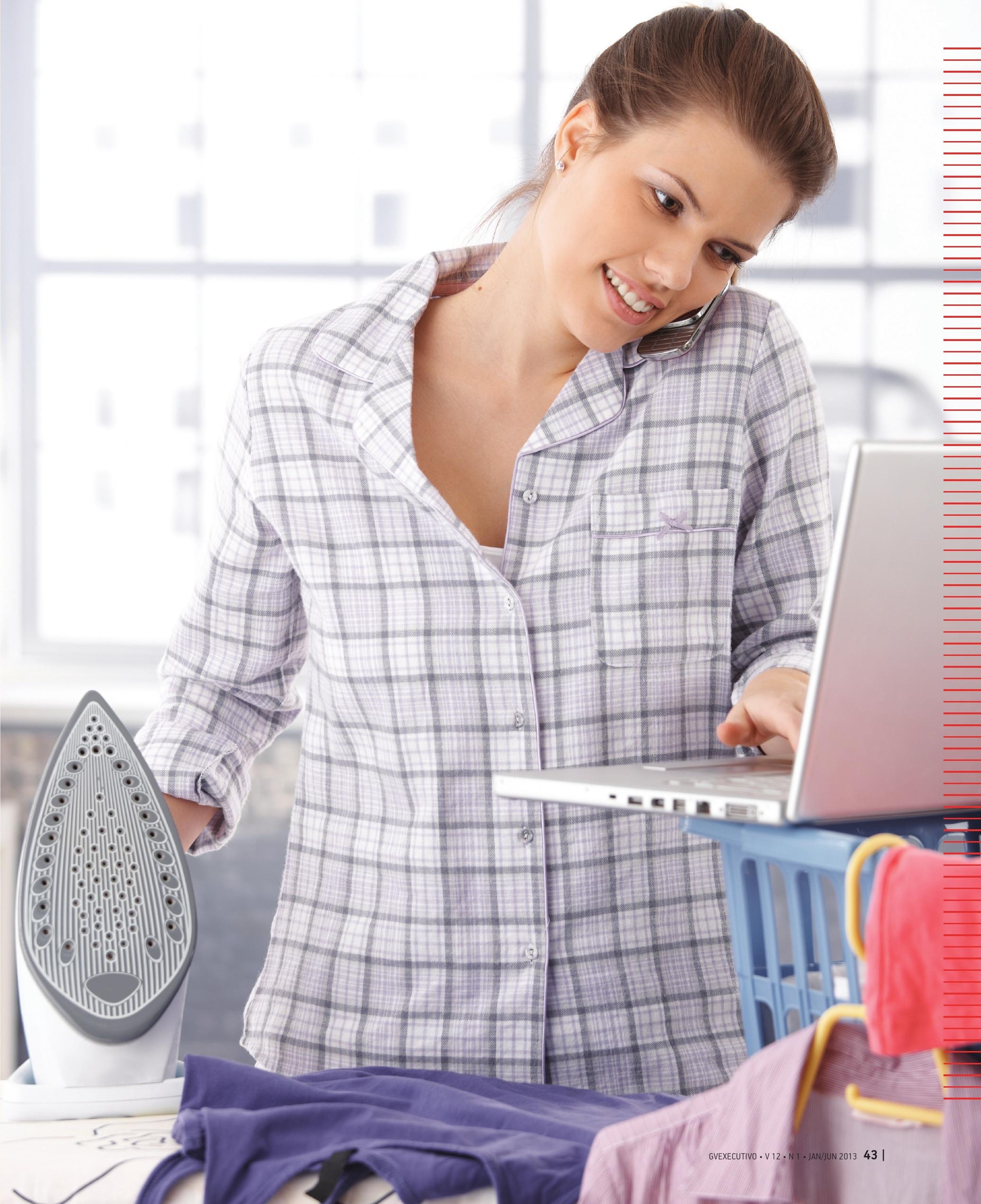


Informações interessantes sobre o avanço dessa participação são o aumento na quantidade de mulheres trabalhando por conta própria (de 36,6 para $39,5 \%$ ) e o crescimento de seu papel como empregadoras (de 27,7 para $30,1 \%$ ) no mesmo período. Esses números convergem para reflexões sobre o potencial produtivo do contingente feminino.

Um aspecto digno de preocupação é o fato de que, nesse mesmo intervalo, a quantia de trabalhadoras sem carteira assinada aumentou $4 \%$, contra apenas $2,7 \%$ das que exercem atividade profissional com registro, o que sugere a ocorrência de informalidades que podem mascarar alguns dos problemas enfrentados pelo público feminino: diferença na remuneração direta e indireta entre os gêneros; fuga de encargos e obrigações legais em períodos de maternidade e aleitamento; e desconsideração de mecanismos compensatórios e de tolerância, que permitem jornadas alternativas para conciliar a rotina de trabalho e os afazeres domésticos.

\section{VALORIZAÇÃO PROFISSIONAL E FAMILIAR}

Ainda que a ocupação das mulheres no mercado de trabalho seja crescente, sua participação no topo das organizações ainda é rara. O fenômeno "teto de vidro" - como é denominada a barreira invisível que impede mais profissionais do sexo feminino de chegarem ao topo - ainda prevalece.

Os casos publicados e proclamados pelas revistas especializadas são frequentemente relatados como exceções (e de fato são), em que a mulher é apresentada como um ser diferenciado e que conta como abriu mão de outros aspectos importantes de sua vida em prol de uma carreira em direção ao topo das organizações.

As questões de gênero direcionam a elas o papel do atendimento às demandas relativas à família e às demais atividades domésticas, atribuindo ao homem maior disponibilidade e dedicação para as questões profissionais.

\section{POSTERGAÇÃO DA MATERNIDADE}

A dificuldade em conciliar tantas responsabilidades diante de grandes desafios e cenários pouco favoráveis tem levado as mulheres a postergarem a maternidade, pois há receio de que o afastamento temporário do mercado de trabalho as torne obsoletas e descartáveis.

Importantes segmentos da sociedade (organizações, profissionais experientes e a mídia) nem sempre contribuem positivamente para melhorar as condições de trabalho desse público; ao contrário, frequentemente nos deparamos com relatos de pessoas que demonstram "grande

\section{Ainda que as mulheres ocupem um número crescente nas posições do mercado de trabalho, sua participacão no topo das organizações é rara. O fenômeno "teto de vidro" ainda prevalece}

senso de dever e preocupação com sua carreira", subordinando importantes e cruciais momentos da vida pessoal e familiar - como sua presença no crescimento dos filhos - às demandas laborais. Elas são apresentadas como modelos a um contingente de trabalhadores muitas vezes inexperientes e novatos, que tenderão a repetir o padrão apresentado como ideal.

\section{O PAPEL FEMININO EM UM CASAL COM CARREIRA DUAL}

As mudanças sociais, econômicas e tecnológicas resultaram no estabelecimento de um novo padrão de carreira, no qual, por um lado, há demandas e preocupações com a trajetória profissional e, por outro, tarefas e obrigações familiares. Em tempos recentes, cada vez mais surgem casais que tentam articular sua atuação nessas duas esferas, equilibrando-se nas novas articulações entre ambas. A essa combinação chamamos carreira dual, ou casal com carreira dual.

Aspectos culturais e econômicos emprestam diferentes tons à palheta de cores do equilíbrio entre vida profissional e familiar, mas estudos denotam a predominância das mulheres em relação aos homens como protagonistas nas tarefas da casa que, entre muitas atribuições, podem incluir a educação dos filhos, a manutenção do lar e o cuidado com parentes idosos ou doentes.

Pesquisas recentes relatam que mesmo entre casais com alta escolaridade e em que marido e esposa sejam profissionais em ascensão, cabe à parte feminina o papel de cuidar das tarefas domésticas. Decorre daí a renúncia de oportunidades profissionais frente às necessidades da família e à carreira do cônjuge. 


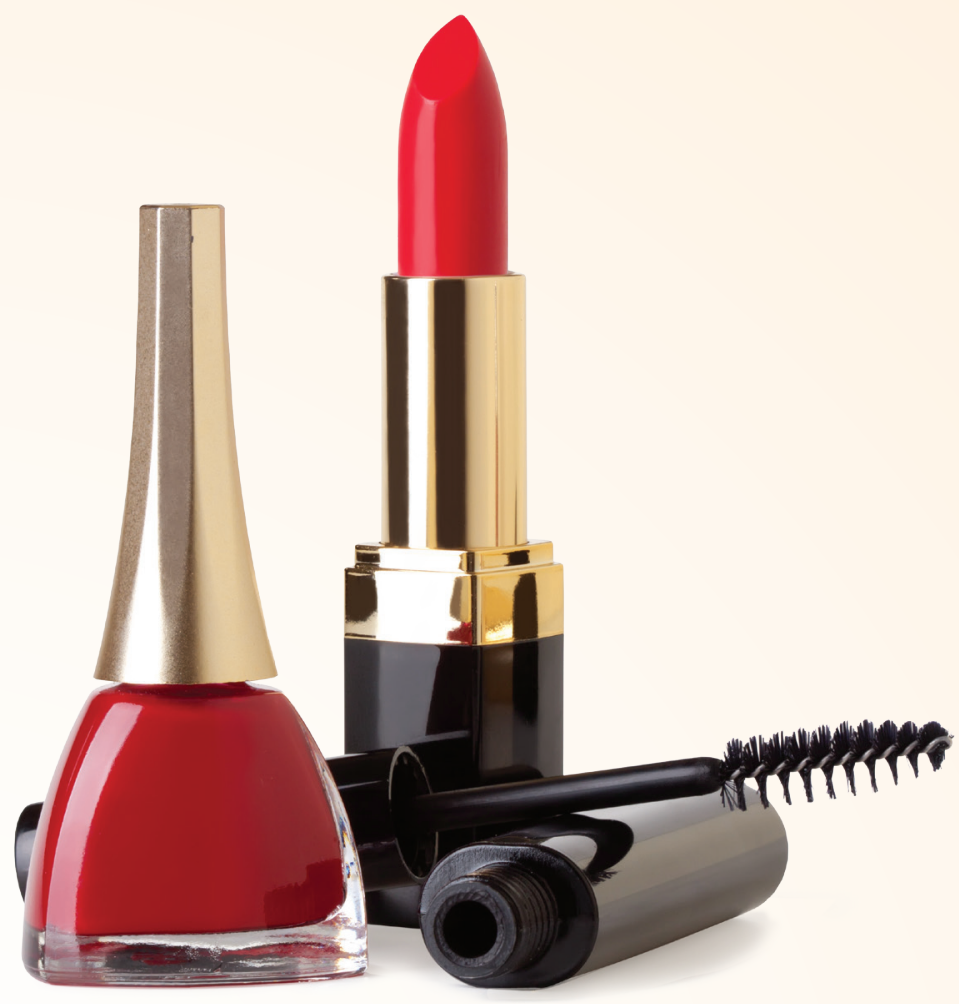

\section{Ao alocar maior tempo na esfera profissional e familiar, o contingente feminino tem relegado a terceiro plano as preocupações com o seu lado pessoal}

\section{TRABALHO E FAMÍLIA, MAS E A VIDA PESSOAL?}

Muito se tem discutido sobre o equilíbrio entre vida profissional e a familiar, principalmente para as mulheres. Novos estudos têm procurado ampliar essas duas arenas para aspectos mais abrangentes como situações de trabalho e de não trabalho. A primeira comporta atividades como: o exercício profissional, programas de desenvolvimento e treinamento, reuniões sociais com objetivos de negócios e o envolvimento em ações voluntárias corporativas. Já na segunda constam todas as demais atuações realizadas fora do âmbito profissional: trabalho voluntário para a comunidade, cuidados com a família, lazer e atividades relacionadas à própria saúde física e mental (ginástica e meditação, por exemplo).

Algumas pesquisas nos ensinam que ao alocar maior tempo na esfera profissional e familiar, as mulheres têm relegado a terceiro plano as preocupações com o seu lado pessoal - curiosamente, são raríssimas as menções voltadas à vida pessoal e individual entre as que exercem atividade remunerada. Decorrências desse descaso têm sido apuradas em estudos sobre saúde física, emocional e satisfação no ambiente corporativo. Ao abrir mão de sua vida particular, o público feminino também restringe suas oportunidades de plena integração no âmbito do trabalho, minimizando suas chances de sucesso subjetivo nesse ambiente.

Em contraposição, os homens têm dedicado mais tempo às atividades individuais e sociais fora de casa, ao mesmo tempo em que encaram algumas tarefas familiares como lazer (almoços, festas em casa e visitas de parentes).
É plenamente compreensível tal aproximação entre descanso, diversão e eventos do lar quando se sabe que na maior parte dos casos cabe à mulher a organização e a realização de tais atividades.

Dividindo-se entre a casa e o trabalho, multiplicando-se em diferentes papéis, somando mais atribuições à sua rotina diária, é de seu lado pessoal que as profissionais subtraem o tempo a ser alocado na carreira ou na convivência familiar.

\section{DESAFIOS PARA AS ORGANIZAÇÕES}

Se por um lado as consequências são preocupantes para as pessoas, por outro também são para as organizações. Empresas que reconhecem a importância de seu capital humano e desejam gerir seus talentos devem buscar a compreensão das peculiaridades do universo feminino no mundo profissional. A complexidade da mulher transcende a esfera do trabalho e, por isso, ela deve ser considerada nas políticas e programas de gestão de pessoas nas organizações - recomendam-se (e requerem-se) oportunidades de ascensão e carreira iguais para tão profundas diversidades.

A síntese é que, em gestão de pessoas nas organizações, tal como nos movimentos da década de 1970, provocados pelo lançamento da obra de Betty Friedan, as questões sobre equilíbrio entre carreira, vida familiar e pessoal não envolvem somente profissionais e mães, envolvem mulheres.

TANIA CASADO > Professora da Faculdade de Economia, Administração e Contabilidade da Universidade de São Paulo (FEA-USP) > tcasado@usp.br 